\title{
Benign Tumours of Nasopharynx-Revisited
}

\author{
Sanjeev Mohanty $\cdot$ M. Gopinath $\cdot$ Mukundan Subramanian
}

Received: 23 June 2011/ Accepted: 16 November 2011/Published online: 30 November 2011

(C) Association of Otolaryngologists of India 2011

\begin{abstract}
Benign tumours of nasopharynx are extremely rare; seen predominantly in children and young adults. Patients usually present with seemingly innocuous symptoms and an error in judgement can be catastrophic. This is a retrospective analysis of patients diagnosed to have benign tumours of nasopharynx by histopathological examination in our tertiary care referral centre. The period of study is from September 2009 to August 2010. Eight patients with complete clinical data were identified and included in the study. All the patients were males with a mean age of 21.37 years (range 10-43). Following surgical excision patients were followed up for a mean period of 6.5 months (range 3-14). The Clinical profile, investigation modalities, treatment options are being analysed here.
\end{abstract}

Keywords Benign tumours - Embolisation - Endoscopic · Epistaxis

\section{Introduction}

Nasopharyngeal masses have a wide range of presentations, attributable to several benign conditions and a high index of suspicion is needed for timely management. Patients usually present late with history of prolonged treatment and accurate diagnosis and early intervention is indicated to prevent complications. Here we describe our experience with management of these rare lesions ranging from Thornwalds cyst to angiofibroma with an aim to

S. Mohanty $(\bowtie) \cdot$ M. Gopinath $\cdot$ M. Subramanian

Department of ENT, Head \& Neck Surgery, Sri Ramachandra

University, Chennai 600116, Tamil Nadu, India

e-mail: drsanjeevmohanty@gmail.com analyze the incidence and presentation of these lesions and standardizing the diagnostic and management options.

\section{Materials and Methods}

Retrospective chart review was performed for all patients who underwent surgical treatment for nasopharyngeal lesions from September 2009 to August 2010 in our tertiary care centre. All malignant lesions were excluded from the study. All cases were operated upon by the same surgeon. Patient demographics, symptomatology, radiological investigations, surgical approach, tumour histology and patient outcome were assessed [11, 13, 14].

\section{Results}

Eight patients had undergone surgical excision for tumours arising from or involving the nasopharynx. The mean age was 21.37 years (range 10-43). All the patients were males and indications for resection were juvenile nasopharyngeal angiofibroma in five cases, craniopharyngioma in one case, Thornwalds cyst in one case and branchial cleft cyst in one case. Two patients underwent external approach surgery and others underwent endoscopic excision. (Table 1) There were no significant post operative complications. No recurrences were reported during the follow up period. The mean follow up period was 6.5 months (range 3-14 months).

Nasal obstruction and epistaxis were the commonest presentation of these tumours [8, 13] (Fig. 1). Anterior rhinoscopy was normal in six patients; only two patients had a mass extending into the nasal cavity visible on anterior rhinoscopy. Physical characteristics of the mass on post nasal examination and diagnostic nasal endoscopy 
Table 1 Patient biodata and tumour characteristics

\begin{tabular}{lllllrrr}
\hline No & Age & Sex & Diagnosis & Approach & $\begin{array}{l}\text { Hospital } \\
\text { stay (days) }\end{array}$ & $\begin{array}{l}\text { Complication/ } \\
\text { recurrences }\end{array}$ & $\begin{array}{l}\text { Follow up period } \\
\text { (months) }\end{array}$ \\
\hline 1 & 10 & M & Craniopharyngioma & Endoscopic & 4 & Nil & 14 \\
2 & 13 & M & JNA & Lateral Rhinotomy & 21 & Nil & 3 \\
3 & 15 & M & JNA & Endoscopic & 7 & Nil & 6 \\
4 & 17 & M & JNA & Transpalatal & 15 & Nil & 12 \\
5 & 41 & M & Thornwald's cyst & Endoscopic & 3 & Nil & 4 \\
6 & 43 & M & Branchial cyst & Endoscopic & 3 & Nil & 5 \\
7 & 18 & M & JNA & Endoscopic & 6 & Nil & 3 \\
8 & 14 & M & JNA & Endoscopic & 5 & Nil & 5 \\
\hline
\end{tabular}

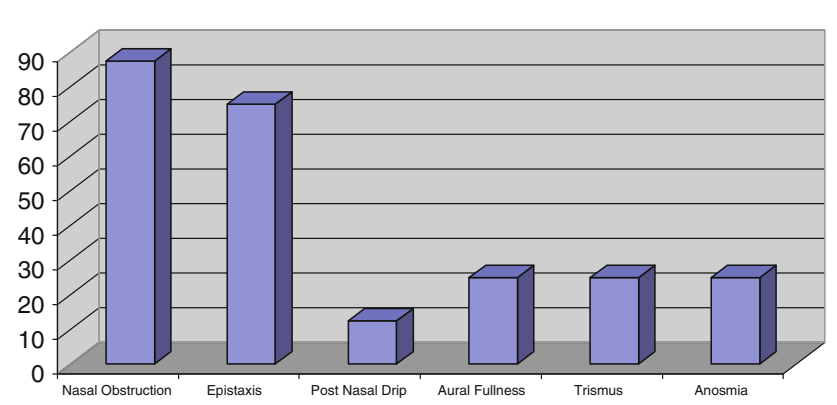

Fig. 1 Shows the symptom profile of the patients. Nasal obstruction and epistaxis are the most prominent symptoms. Trismus and aural fullness was seen associated with particularly large tumours of the nasopharynx

(Fig. 2) were similar and non-specific; attributable to any benign lesion. All patients underwent CT/MRI of nose and paranasal sinuses (Figs. 3, 4). Patients with contrast

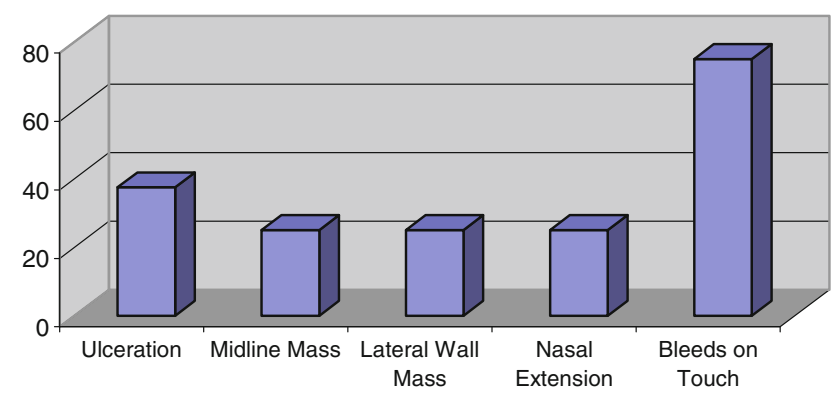

Fig. 2 Summarises the DNE findings; most patients had a well defined mass limited to the nasopharynx; majority of them bled on touch; and few had surface ulceration

enhancing mass underwent digital subtraction angiography, followed by embolisation $48 \mathrm{~h}$ prior to surgery (Fig. 5).

All the patients were operated under general anaesthesia with nasal decongestion and local infiltration with 1 in 2 lakhs
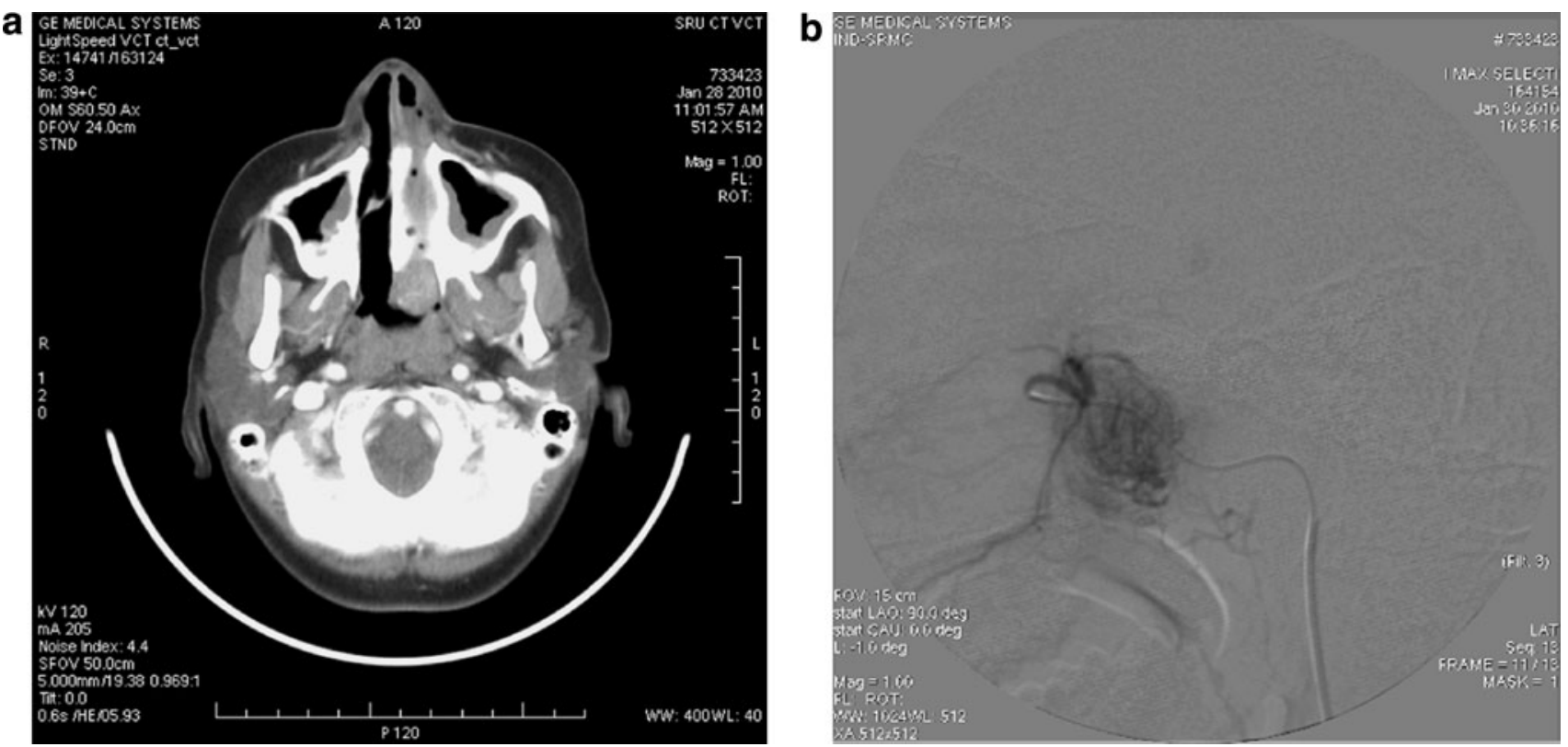

Fig. 3 a Shows an enhancing mass in the left side of nasopharynx obstructing the choana. b Shows the angiographic picture with tumor blush 


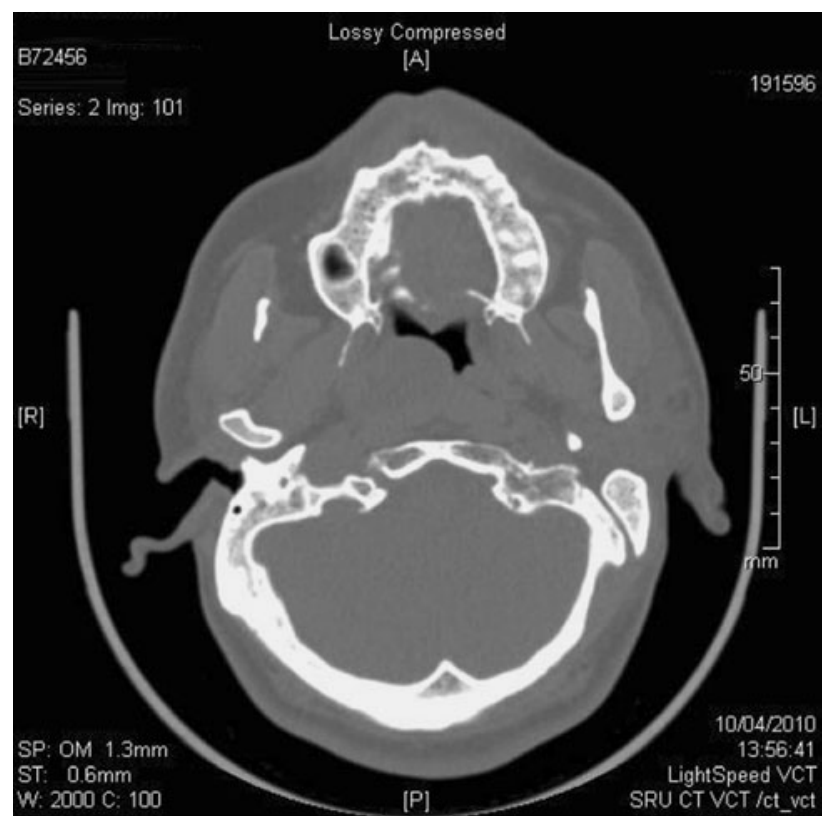

Fig. 4 Shows homogenous soft tissue dense, non enhancing mass involving the right lateral wall of nasopharynx, with obliteration of RT parapharyngeal pad of fat

dilution of Xylocaine with adrenaline. Nasal pack was kept in situ for 24-48 h post operatively. Patients were discharged with oral antibiotics and saline nasal douching. Endoscopic toileting was done at 1 week, 1 month and 3 months.

\section{Discussion}

Primary tumours of nasopharynx are rare. Vascular tumours account for more than 50\% of benign non epithelial nasopharyngeal lesions [4]. Congenital anomalies, hematolymphoid, bony and cartilaginous tumours account for the rest $[1,13]$. The clinical presentation is often the same and a blind attempt to curettage or biopsy can be detrimental [10]. High index of suspicion and appropriate radiological investigations to assess the morphology, size and extent of tumour are required for proper planning and management [9]. Surgical accesses to nasopharynx are many including the external and endoscopic approaches. External approaches are inferiorly-via a trans-palatal route; laterally via a transtemporal or infratemporal route; anteriorly via a maxillary swing approach $[3,15]$. These approaches have limited access and considerable post op morbidity due to extensive and complex mobilization [12, 14, 15]. Transnasal endoscopic resection of nasopharyngeal tumours obviates the need for extensive soft tissue and bony mobilization [2, 6]. Endoscopes provide excellent visualization in terms of illumination and magnification, but the anatomical limits to this approach necessitates the use of external approaches for complete tumour resection in large and extensive juvenile nasopharyngeal angiofibromas. Preoperative angiography and embolisation reduces intra op bleeding and improves outcome [7].

\section{Conclusion}

Our small series of patients with similar symptomatology and varied pathology emphasizes the need for radiological evaluation. JNA was the commonest benign nasopharyngeal tumour of the nasopharynx [5]. Planning of surgical approach depends on size and extent of the tumour as
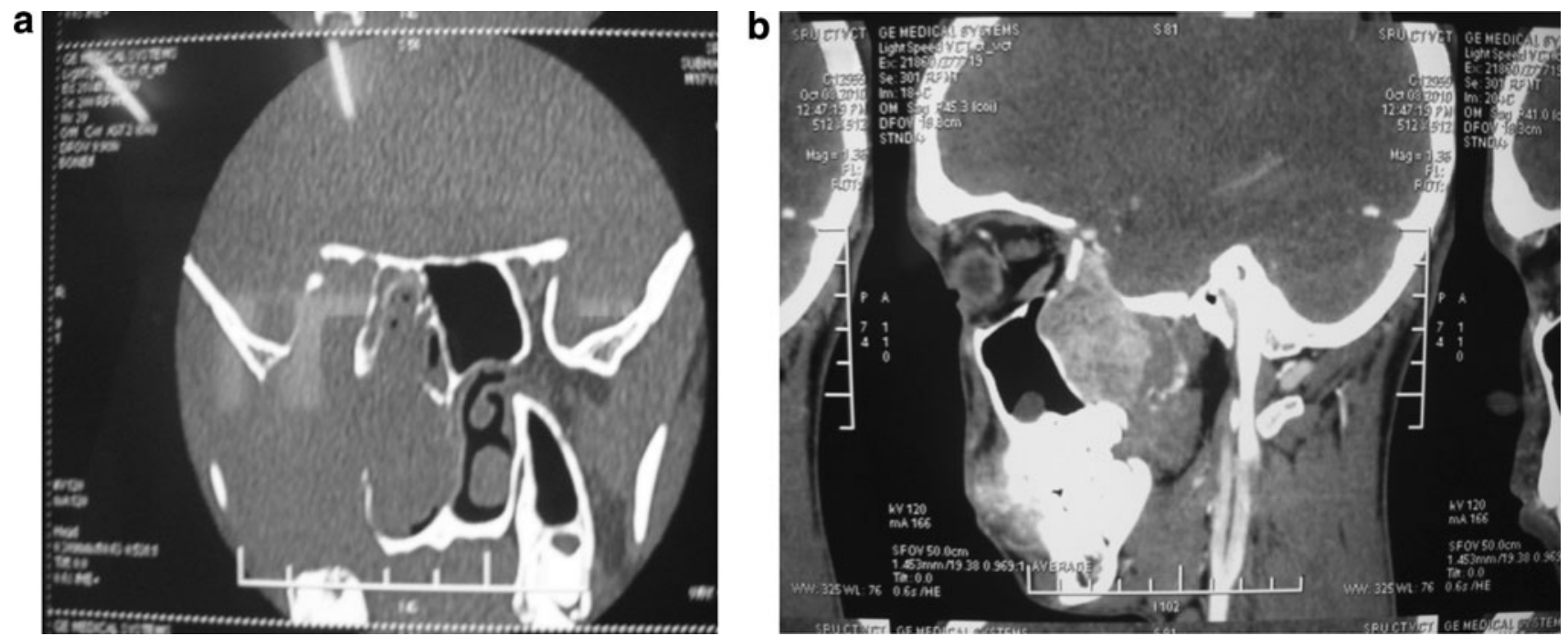

Fig. 5 a Shows CT PNS coronal view with a homogenous contrast enhancing mass involving right nasal cavity and maxillary sinus. b Sagittal section showing involvement of the pterygopalatine and infratemporal fossa, necessitating an external approach 
assessed by radiological investigations [8]. Surgical outcome of patients treated by external and endoscopic approaches is same with no complications or recurrences in a mean follow up period of 6.5 months.

\section{References}

1. Baradaranfar M-H, Dabirmoghaddam P (2006) Endoscopic endonasal surgery for resection of benign sinonasal tumors. Arch Iran Med 9(3):244-249

2. Carrau RL, Snyderman CH, Kassam AB et al (2001) Endoscopic and endoscopicassisted surgery for juvenile angiofibroma. Laryngoscope 111:483-487

3. Fisch U (1983) The infratemporal fossa approach for nasopharyngeal tumors. Laryngoscope 93:36-44

4. Fu YS, Perzin KH (1974) Non-epithelial tumors of the nasal cavity, paranasal sinuses, and nasopharynx: a clinicopathologic study I. General features and vascular tumors. Cancer 33:1275-1288

5. Gnepp DR (2001) Diagnostic surgical pathology of the head and neck. In: Anonymous. WB Saunders, Philadelphia, pp 96

6. Kamel RH (1996) Transnasal endoscopic surgery in juvenile nasopharyngeal angiofibroma. J Laryngol Otol 110:962-968

7. Leong JL, Batra PS, Citardi MJ (2006) CT-MR image fusion for the management of skull base lesions. Otolaryngol Head Neck Surg 134:868-876
8. Moorthy PNS, Reddy BR, Qaiyum HA, Srivalli M, Srikanth K (2010) Management of juvenile nasopharyngeal angiofibroma: a five year retrospective study. Indian J Otolaryngol Head Neck Surg 62(4):390-394

9. Paris J, Guelfucci B, Moulin G, Zanaret M, Triglia JM (2001) Diagnosis and treatment of juvenile nasopharyngeal angiofibroma. Eur Arch Otorhinolaryngol 258(3):120-124S

10. Pasquini E, Sciarretta V, Frank G, Cantaroni C, Modugno GC, Mazzatenta D (2006) Endoscopic treatment of benign tumors of nose and paranasal sinuses. Am J Rhinol 20(1):64-71

11. Pirris SM, Pollack IF, Snyderman CH et al (2007) Corridor surgery: the current paradigm for skull base surgery. Childs Nerv Syst 23:377-384

12. Radkowski D, McGill T, Healy GB et al (1996) Angiofibroma changes in staging and treatment. Arch Otolaryngol Head Neck Surg 122:122-129

13. Sen S, Saha S, Basu N (2004) Clinical study of benign tumors of nose and paranasal sinuses. Indian J Otorhinolaryngol 56(4): 265-268

14. Tandon DA, Bahadur S, Kacker SK et al (1988) Nasopharyngeal angiofibroma: (a nine-year experience). J Laryngol Otol 102:805-809

15. Wei WI, Ho CM, Yuen PW, Fung CF, Sham JS, Lam KH (1995) Maxillary swing approach for resection of tumors in and around the nasopharynx. Arch Otolaryngol Head Neck Surg 121:638-642 